\title{
Research af the General Post Office
}

\author{
from our Special Correspondent
}

THE healthy range of short term projects under way at the Post Office research laboratories in Dollis Hill should not be allowed to conceal the relegation of basic research to a level that must cause some concern. Although the Post Office is affected by uncertainty about its future status, and senior officials deserve some sympathy in their efforts to recruit new staff on the rigid scale of pay of the civil service, the danger of impending change being used as a pretext for procrastination should not be overlooked.

The chief dilemma facing the Post Office is that it is attempting to fulfil several conflicting roles. It is supposed to provide a service to the country, and yet be a commercial success; it is asked to plan a communications network to encompass the future needs of the country, and yet is denied the administrative machinery to enable it to compete effectively for the scientific manpower it requires. Within the framework of these constrictions, which hopefully will be loosened (within a year or so) by a new constitution, the research laboratories are busy making sure that they at least win the next few rounds of technological advance.

The research and development budget for the year 1967-8 shows an overall increase of about 25 per cent over that of the previous year, with exchange equipment and circuitry being the principal beneficiaries.

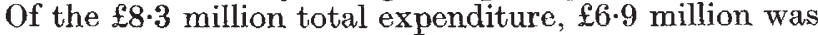
spent on telecommunications research, and the breakdown of this figure is shown in the accompanying table. The rise in research into overseas services is claimed to be due to the need to fulfil existing contracts, and runs counter to the general policy of the department.

The remainder of the $£ 8 \cdot 3$ million was swallowed up by work on postal plant and by various accommodation services.

\begin{tabular}{ccc}
\multicolumn{2}{c}{ RESEARCH AND DEVELOPMENT EXPENDITURE ON } \\
\multicolumn{3}{c}{ TELECOMMUNICATIONS PLANT } \\
$1966-7$ & Project & $1967-8$ \\
$\left(£ \times 10^{3}\right)$ & & $\left(£ \times 10^{3}\right)$ \\
1,050 & Trunk and junction circuits & 1,460 \\
400 & Local lines & 360 \\
530 & Subscribers eircuits & 580 \\
1,970 & Exchange equipment & 2,420 \\
300 & Telegraph equipment & 350 \\
1,480 & Overseas services & 1,760 \\
$-7,730$ & Total & $\mathbf{6 , 9 3 0}$
\end{tabular}

The pressure for research work in the Post Office stems from two principal sources; the customer, who must be supplied with the desired brand of equipment, be it a new undersea cable or a more efficient telephone exchange; and the materials industries, which turn out new plastics or fibres whose potential for telecommunications has to be investigated. Sandwiched between these two endeavours lies the design of new circuitry and devices suitable for general application in the Post Office.

There is no lack of outlets for inventiveness in such an expanding concern. Pulse code modulation (PCM) techniques have passed beyond the stage of field trials and are likely to replace conventional analogue methods on an ever increasing scale. To keep pace with this, such problems as the efficiency of switching devices in telephone exchanges, or the need for multichannel transmission media to cope with the vast output of digital information that will have to be conveyed around the country, are receiving serious attention. The site at Martlesham Heath in Suffolk, which is destined to house the Post Office research laboratories after 1972 , is already host to an experiment to test whether different models of waveguide are suitable as communication lines along heavily populated routes. This is a venture undertaken jointly with a university research group. Collaboration with industry, however, occurs more frequently than with universities, and in some spheres-as with the computer industry-the Government department is riding squarely on industry's shoulders. This is sensible, because duplication of work is pointless. But it is also imperative that the enthusiasm generated by research workers being able to pursue their projects to logical as well as commercial conclusions should not be missing from a department that requires vision as much as practicality.

Progress in adapting microcircuits to the demands of PCM is certainly afoot, involving probes into the properties of metal-oxide-silicon devices and the technology of constructing reliable and cheap specimens, but has the question of the optimum size for departments working on topies with such potential been seriously enough considered ? Perhaps this is an example of how day to day events can mould the structure of a department into a form which appears quite consistent on the surface and yet hides a more radical malaise beneath. For in several departments at the research station there seems to be room for an expansion of activity which is accepted as wholly desirable, but which is thwarted as much by prescribed bounds to the Post Office as a whole as by the values expressed in the civil service hierarchy.

There are several countries which have similar communications problems to those of Britain, and similar aspirations as well. Have all the avenues for international collaboration been fully explored? Or has the export potential for the new techniques which the Post Office is pursuing been sized up in relation to current research expenditure? Such tasks are no doubt difficult, and preoccupation with home demand clearly takes up much of the available resources, but an awareness of the possibilities here deserves some emphasis.

Work now in progress on lasers, semiconductors, microcircuits and waveguides is likely to be transformed into some of the technological cream of the seventies, and it needs some organized drive to make sure that those scientists and technologists who could contribute most significantly to this process are not rebuffed by rigidity or a lack of glamour. Many of the problems are as challenging as those devoured with relish at the universities, and it is to be hoped that the full scale removal of the research laboratories to Suffolk will provide the spur for some radical thinking in this regard. 